\title{
Education and training for technicians in photonics-enabled technologies
}

Daniel Hull, Darrell Hull

Daniel M. Hull, Darrell M. Hull, "Education and training for technicians in photonics-enabled technologies," Proc. SPIE 9664, Ninth International Topical Meeting on Education and Training in Optics and Photonics, 96641W (24 October 2005); doi: 10.1117/12.2207676

Event: Ninth International Topical Meeting on Education and Training in Optics and Photonics, 2005, Marseille, France 


\section{Ref ETOP022}

\section{Education and Training for Technicians in Photonics-Enabled Technologies}

Daniel M. Hull, CORD, and Darrell M. Hull, PhD, Baylor University

\section{Summary}

Within a few years after lasers were first made operational in 1960, it became apparent that rapid growth in the applications of this new technology in industry, health care, and other fields would require a new generation of technicians in laser/optics engineering. Technicians are the men and women who work alongside scientists and engineers in bringing their ideas, designs, and processes to fruition. In America, most highly qualified technicians are graduates of associate of applied science (AAS) programs in community and technical colleges (two-year postsecondary institutions). Curricula and educational programs designed to prepare technicians in laser/electro-optics technology (LEOT) emerged in the 1970s; today there are over 15 LEOT programs in the United States producing over 100 LEOT graduates each year. Those graduates are in high demand.

With the emergence of numerous medical and telecommunication applications in the 1980s, including fiber-optics, the field of laser/electro-optics evolved into photonics, a broad field encompassing optoelectronics, micro-optics, lasers, digital imaging, spectroscopy, optical instruments, and optical systems.

Photonics applications continue to expand. Today photonics is not only a technology field in and of itself; it is also an enabler of nearly every other technology field, including microtechnology, measurement and materials processing, remote sensing, photolithography for semiconductors, nanotechnology, electro-optics displays and imaging, and homeland security. All of the technology fields of the American Association of Community Colleges' Pathways to Technology involve optics and photonics technology (http://www.pathwaystotechnology.org/).

\section{Photonics-An Enabling Technology}

Aerospace technology-Uses LiDAR (laser RADAR systems) and laser altimeters, imaging systems for test and analysis of aircraft, holographic heads-up displays, and optical pattern recognition systems for navigation - Agricultural technology-Uses satellite remote sensing to detect large-scale crop effects, scanning technology and infrared imaging to monitor food production and quality, and sensor systems for planting and irrigation - Biomedical technology-Uses lasers for surgery, therapies such as photodynamic therapy, and in situ keratomileusis (LASIK) procedures; uses testing and analysis devices such as noninvasive glucose monitors - Construction technologyIncludes scanning site topography, laser bar-code readers to inventory materials, and three-dimensional analysis to track the progress of construction - Engineering, microtechnology, and nanotechnology-Uses lasers in manufacture of electrical devices, motors, engines, semiconductors, circuits, and computers. Via photolithography, photonics is central to mems production. - Environmental technology-Uses ultraviolet doppler optical absorption spectroscopy (UV-DOAS) to monitor air quality, and uses fast fourier transform analysis to monitor particulate matter in effluents released from stacks - Geographic information systems and global positioning-Uses photonics technology in imaging and image processing to refine 
atmospheric and space-based images - Information technology-Uses optics for data storage, ultrafast data switching, and (especially) for transmission of data across fiberoptic networks - Chemical technology-Relies on molecular optical spectroscopy for analysis and on ultrashort laser pulses to induce fluorescence in materials. In addition, chemical vapor deposition and plasma etching support photonics thin-film applications. • Transportation technology-Uses optics for monitoring exhaust emissions to ensure the integrity of shipping containers arriving from foreign ports and for navigation with ring laser gyroscopes - Homeland security-Uses optics and lasers for forensics, surveillance, monitoring, and personal identification

Projected Demand for Photonics Technicians-Rapid growth in the number and complexity of photonics and photonics-enabled technologies has caused the demand for technicians to grow despite a national economic downturn. According to a recent survey of employers, the number of U.S. technical jobs in photonics and photonics-enabled technologies is expected to grow more than 1800/year on average through 2009 , an increase of more than $6 \%$ per year. ${ }^{1}$

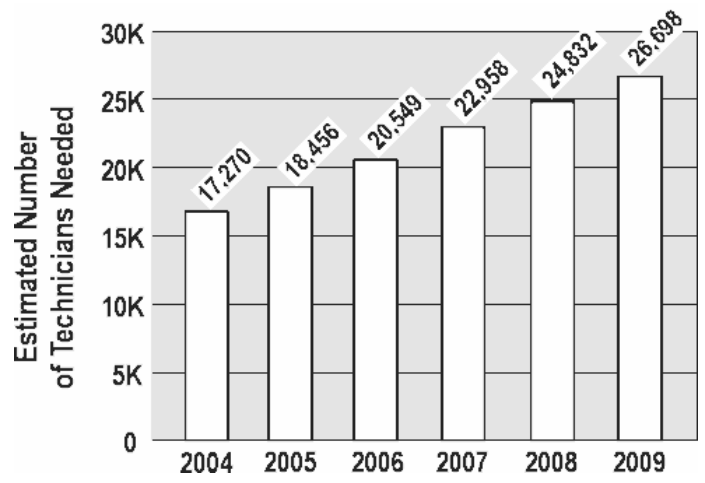

Growth in the demand for technicians in photonics and photonics-enabled technologies has in turn created a need for new educational programs and tools. While two-year AAS and one-year certificate programs in optics, laser/electro-optics, and photonics exist, the availability of programs and supporting materials is far from adequate. Moreover, the gap between the educational status quo and the realities of the marketplace-particularly in photonics-enabled technologies-is about to become much wider, given changes that the field is undergoing. Recognition of this fact among educators was recently brought to light under the STEP II (Scientific and Technological Education in Photonics, NSF DUE/ATE 0202424) pilot program, in which 36 colleges expressed interest in using STEP's photonics fundamentals courses as electives in photonics-enabled fields.

Although some colleges with full AAS degree programs in optics and photonics will continue to use the STEP instructional materials, a decision has been made to focus future curriculum development on the needs of institutions that offer programs in

\footnotetext{
${ }^{1}$ Darrell Hull and Agustin Navarra, "Photonics Technician Employment Projections: An Industry Survey Report" (unpublished manuscript). Projections based on survey responses from an available population of businesses taken from the Laurin Publishing Company's Corporate Directory.
} 
photonics-enabled technologies. It is recommended that those institutions infuse into their programs all or part of the following two courses, for which STEP instructional materials (student modules) have been completely developed and tested in pilot courses at colleges:

\section{Course 1. Fundamentals of Light and Lasers}

Module 1. Nature and Properties of Light

Module 2. Optical Handling and Positioning

Module 3. Light Sources and Laser Safety

Module 4. Basic Geometrical Optics

Module 5. Basic Physical Optics

Module 6. Principles of Lasers

\section{Course 2. Elements of Photonics}

Module 1. Operational Characteristics of Lasers

Module 2. Specific Laser Types

Module 3. Optical Detectors and Human Vision

Module 4. Principles of Optical Fiber Communication

Module 5. Photonic Devices for Imaging, Storage, and Display

Module 6. Basic Principles and Applications of Holography

In addition, the following application modules have been (or are being) developed:

A. Lasers in Medicine and Surgery

B. Medical Laser Types/Characteristics and Laser Diagnostics (under development)

C. Laser Welding and Surface Treatment

D. Laser Material Removal: Drilling, Cutting, and Marking

E. Laser Testing and Measurement: Alignment, Profiling, and Position Sensing

F. Lasers in Testing and Measurement: Interferometric Methods and NDT

G. Lasers in Forensic Science and Homeland Security

H. Laser Spectroscopy in Environmental Sensing (under development)

Additional application modules will be developed as the need arises.

How will photonics instruction be infused into instruction in other technologies?-Each STEP module is a "stand-alone" unit of instruction containing learning objectives, presentation of content, demonstrations, example problems, laboratory exercises, problem assignments, and references. The relative independence of the modules allows them to be grouped in combinations that tailor their content to the optics/photonics aspects of a wide variety of technologies. For instance, in manufacturing, two laser/optics courses could be taught. The modules in Course 1 would constitute a onesemester course. The second-semester course would be constructed using the first three modules from Course 2, plus application modules C, D, E, and F. Other selections could be made as appropriate to the teaching content required in other technologies. 